\title{
Association of mitotane with chylomicrons and serum lipoproteins: practical implications for treatment of adrenocortical carcinoma
}

\author{
Matthias Kroiss ${ }^{1,3}$, Dietmar Plonné ${ }^{4}$, Sabine Kendl ${ }^{1}$, Diana Schirmer ${ }^{2}$, \\ Cristina L Ronchi ${ }^{6}$, Andreas Schirbel ${ }^{5}$, Martina Zink ${ }^{1}$, Constantin Lapa ${ }^{5}$, \\ Hartwig Klinker ${ }^{2}$, Martin Fassnacht ${ }^{1,3,6}$, Werner Heinz ${ }^{2}$ and Silviu Sbiera ${ }^{3}$
}

${ }^{1}$ Endocrine and Diabetes Unit, Department of Internal Medicine I, ${ }^{2}$ Infectiology Unit, Department of Internal Medicine II, University Hospital Würzburg, Oberdürrbacher Street 6, 97080 Würzburg, Germany, ${ }^{3}$ Comprehensive Cancer Center Mainfranken, University of Würzburg, Würzburg, Germany, ${ }^{4}$ Division of Laboratory Medicine, Medical Care Centre of Human Genetics UIm, Ulm, Germany, ${ }^{5}$ Department of Nuclear Medicine, University Hospital Würzburg, Würzburg, Germany and ${ }^{6} \mathrm{Clinical}$ Chemistry and Laboratory Medicine, University Hospital Würzburg, Würzburg, Germany

\author{
Correspondence \\ should be addressed \\ to $M$ Kroiss \\ Email \\ Kroiss_M@ukw.de
}

\begin{abstract}
Objective: Oral mitotane (o, $\left.\mathrm{p}^{\prime}-\mathrm{DDD}\right)$ is a cornerstone of medical treatment for adrenocortical carcinoma (ACC).

Aim: Serum mitotane concentrations $>14 \mathrm{mg} / \mathrm{l}$ are targeted for improved efficacy but not achieved in about half of patients. Here we aimed at a better understanding of intestinal absorption and lipoprotein association of mitotane and metabolites $0, p^{\prime}$-dichlorodiphenylacetic acid (o, $p^{\prime}$-DDA) and o, $p^{\prime}$-dichlorodiphenyldichloroethane (o, $p^{\prime}$-DDE).

Design: Lipoproteins were isolated by ultracentrifugation from the chyle of a 29 -year-old patient and serum from additional 14 ACC patients treated with mitotane. HPLC was applied for quantification of mitotane and metabolites. We assessed $\mathrm{NCl}-\mathrm{H} 295$ cell viability, cortisol production, and expression of endoplasmic reticulum (ER) stress marker genes to study the functional consequences of mitotane binding to lipoproteins.

Results: Chyle of the index patient contained $197 \mathrm{mg} / \mathrm{ml}$ mitotane, $53 \mathrm{mg} / \mathrm{ml}$ o, $\mathrm{p}^{\prime}-\mathrm{DDA}$, and $51 \mathrm{mg} / \mathrm{l}$ o, $\mathrm{p}^{\prime}-\mathrm{DDE}$. Of the total mitotane in serum, lipoprotein fractions contained $21.7 \pm 21.4 \%$ (VLDL), $1.9 \pm 0.8 \%$ (IDL), 8.9 $\pm 5.5 \%$ (LDL1), 18.9 $\pm 9.6 \%$ (LDL2), $10.1 \pm 4.0 \%$ (LDL3), and $26.3 \pm 13.0 \%$ (HDL2). Only $12.3 \pm 5.5 \%$ were in the lipoprotein-depleted fraction.

Discussion: Mitotane content of lipoproteins directly correlated with their triglyceride and cholesterol content. O, $\mathrm{p}^{\prime}$-DDE was similarly distributed, but $87.9 \pm 4.2 \%$ of $0, p^{\prime}$-DDA found in the HDL2 and lipoprotein-depleted fractions. Binding of mitotane to human lipoproteins blunted its anti-proliferative and anti-hormonal effects on $\mathrm{NCl}-\mathrm{H} 295$ cells and reduced ER stress marker gene expression.

Conclusion: Mitotane absorption involves chylomicron binding. High concentrations of $0, \mathrm{p}^{\prime}$-DDA and o, $\mathrm{p}^{\prime}$-DDE in chyle suggest intestinal mitotane metabolism. In serum, the majority of mitotane is bound to lipoproteins. In vitro, lipoprotein binding inhibits activity of mitotane suggesting that lipoprotein-free mitotane is the therapeutically active fraction.
\end{abstract}

\section{Introduction}

Adrenocortical carcinoma (ACC) is a rare tumor with dismal prognosis (see $(1,2)$ for recent reviews). Mitotane (1-(2-chlorophenyl)-1-(4-chlorophenyl)-2,2-dichloroethane, o, $\mathrm{p}^{\prime}$-DDD) has been clinically used for treatment of ACC for decades (3) either as monotherapy or in combination with cytotoxic chemotherapies $(4,5)$. Only recently our laboratory identified sterol O-acyltransferase 1 (SOAT1) as a key target of mitotane. We have shown that SOAT1 inhibition by mitotane leads to intracellular accumulation of toxic lipids which results in activation (c) 2016 European Society of Endocrinology Printed in Great Britain
Published by Bioscientifica Ltd. 
of the endoplasmic reticulum (ER) stress response which in turn results in reduced steroidogenesis and apoptosis (6) of ACC cells.

Mitotane treatment is hampered by the requirement of therapeutic drug monitoring and unfavorable pharmacokinetic properties $(7,8)$.

Several studies reported an association of mitotane serum concentrations above $14 \mathrm{mg} / \mathrm{l}$ with treatment response $(9,10,11,12,13)$. Since serum concentrations $>20 \mathrm{mg} / \mathrm{l}$ are associated with more frequent and more severe adverse effects (14), serum concentrations between 14 and $20 \mathrm{mg} / \mathrm{l}$ are aimed at $(15,16)$. However, even with high doses of mitotane for 3 months, concentrations $>14 \mathrm{mg} / \mathrm{l}$ are achieved in only half of patients $(17,18)$ and are never reached in some patients. The reasons for this are unknown.

The long time interval required for reaching effective mitotane serum concentrations is directly related to the excessively long elimination half-live of mitotane which approaches up to 6 months (19). Alkyl oxidation of mitotane leads to formation of the inactive metabolite (20) o, $\mathrm{p}^{\prime}$-dichlorodiphenylacetic acid (o,p'-DDA) (20), which is present in blood in up to tenfold higher concentrations compared to the parent compound and is excreted in urine (21). In contrast, the second metabolite $\mathrm{o}, \mathrm{p}^{\prime}$-dichlorodiphenyldichloroethane (o, $\mathrm{p}^{\prime}$-DDE) is much less abundant (22).

Mitotane has been previously reported to be associated with lipoproteins in serum $(23,24)$, and it has been suggested that mitotane binding to lipoprotein particles may contribute to the apparent tissue specificity of the adrenal cortex. Since adrenocortical cells require large amounts of cholesterol for steroidogenesis, it appears conceivable that lipoprotein binding might favor entry of mitotane into adrenocortical cells similar to a Trojan horse. Recently, lipoprotein association of mitotane has been studied in more detail (25), and lipoprotein-free mitotane reported to confer cytotoxicity in cell culture disproving this hypothesis. It is also known that mitotane treatment increases serum LDL cholesterol which has been attributed to increased hepatic cholesterol synthesis $(26,27)$.

Here we report a translational study starting with the analysis of mitotane in the chyle of a 29-year-old mitotane-treated ACC patient to gain insights into mitotane absorption in the intestine. Subsequently, we challenged data published previously by analyzing association of mitotane and metabolites with serum lipoproteins (25) in 14 additional patients. Cell culture assays were used to study the functional consequences of the association of mitotane with chylomicrons and serum lipoproteins.

\section{Subjects and methods}

\section{Chemicals}

Mitotane for in vitro treatment was from ISP Chemical Products (Columbus, OH, USA), o, $\mathrm{p}^{\prime}$-DDD, o, $\mathrm{p}^{\prime}$-DDE and $p, p^{\prime}$-DDE for HPLC were from Sigma (PESTANAL), and all buffers and solvents from Merck unless otherwise stated.

Iodixanol was supplied as $60 \% \mathrm{w} / \mathrm{v}$ solution (OptiPrep) by Axis-Shield PLC (Dundee, UK). OptiSeal tubes $(3.2 \mathrm{ml})$ were supplied by Beckman Coulter (Krefeld, Germany).

Triacylglycerol, cholesterol, LDL cholesterol, HDL cholesterol assays, calibrators, and serum lipid control levels I and II were purchased from Roche. All lipid measurements were performed on the Cobas C501 from Roche.

\section{Synthesis of DDA}

$\mathrm{o}, \mathrm{p}^{\prime}$-DDA was synthesized as described in Supplementary data, see section on supplementary data given at the end of this article.

\section{HPLC}

Stock solutions of o,p'-DDD $(250 \mu \mathrm{g} / \mathrm{ml}), \quad$ o, $\mathrm{p}^{\prime}$-DDA $(500 \mu \mathrm{g} / \mathrm{ml}), \quad \mathrm{o}, \mathrm{p}^{\prime}$-DDE $(50 \mu \mathrm{g} / \mathrm{ml}), \quad$ and $\mathrm{p}, \mathrm{p}^{\prime}$-DDE $(250 \mu \mathrm{g} / \mathrm{ml}$, internal standard) respectively were prepared in acetonitrile $(\mathrm{AcN})$. Working solutions of $\mathrm{o}, \mathrm{p}^{\prime}-\mathrm{DDD}$ (25 $\mu \mathrm{g} / \mathrm{ml}), o, p^{\prime}$-DDA $(50 \mu \mathrm{g} / \mathrm{ml})$, and o,p'-DDE $(5 \mu \mathrm{g} / \mathrm{ml})$ were prepared in $\mathrm{AcN}$ and stored at $-20^{\circ} \mathrm{C}$. Seven different calibration samples were prepared by accurately spiking $250 \mu \mathrm{l}$ of $5 \% \mathrm{BSA}$ (in $\mathrm{H}_{2} \mathrm{O}$ ) with stock and working solutions to realize calibration ranges of $o, p^{\prime}$-DDD $0.5-40 \mu \mathrm{g} / \mathrm{ml}, \mathrm{o}, \mathrm{p}^{\prime}$-DDA $1.25-100 \mu \mathrm{g} / \mathrm{ml}$, and of $\mathrm{o}, \mathrm{p}^{\prime}$-DDE $0.25-20 \mu \mathrm{g} / \mathrm{ml}$. A volume of $25 \mu \mathrm{l}, \mathrm{p}^{\prime}$-DDE was added to $250 \mu \mathrm{l}$ aliquots of calibration samples or serum and iodixanol gradient fractions, mixed with $250 \mu \mathrm{l}$ of $0,1 \mathrm{~N}$ sodium acetate $\mathrm{pH}$ 4.6. In total, $5 \mu \mathrm{l}$ ascites were used to minimize matrix interferences. Analyte extraction was performed by adding twice $3 \mathrm{ml}$ each of tert-butyl methyl ether for $5 \mathrm{~min}$, followed by centrifugation at $5000 \boldsymbol{g}$ for $5 \mathrm{~min}$. The organic layer was transferred into glass tubes and evaporated to dryness $\left(40^{\circ} \mathrm{C}\right)$ under a gentle stream of nitrogen. The residue was reconstituted with $125 \mu$ of AcN and diluted with $125 \mu \mathrm{l} \mathrm{H}_{2} \mathrm{O}-0.1 \%$ trifluoroacetic acid (TFA) adjusted to $\mathrm{pH} 3.0$ with triethylamine (TEA). A volume of $10 \mu \mathrm{l}$ of this solution was injected into the HPLC system. 
Quantitative analysis was performed on a Hitachi LaChrom Ultra HPLC system (VWR, Darmstadt, Germany) equipped with a L-2160 solvent pump, a L-2455U UV-VIS photodiode array detector, a L-2200 autosampler and a L-2350 column oven. Chromatographic separation of analytes was carried out on ASCENTIS Express C18 column $(100 \times 2.1 \mathrm{mM} / 2.7 \mu \mathrm{M}$; SUPELCO $)$ protected by a C18 guard column $(4 \times 2 \mathrm{mM}$ ID; Phenomenex, Aschaffenburg, Germany) using a linear gradient A/B 50\%-0-5 min-90\% $\mathrm{B} \rightarrow 90 \% \mathrm{~B} / 3.5 \mathrm{~min} \rightarrow 50 \% \mathrm{~B}$ in $0.5 \mathrm{~min} \rightarrow 6.5 \mathrm{~min}$ re-equilibration. The mobile phase A consisted $0.1 \%$ TFA adjusted to $\mathrm{pH} 3.0$ with TEA and AcN (70:30, v/v solvent A; 10:90, $\mathrm{v} / \mathrm{v}$ solvent $\mathrm{B}$ ). The flow rate was $0.2 \mathrm{ml} / \mathrm{min}$, and the column was maintained at $40^{\circ} \mathrm{C}$. Detection was performed at $230 \mathrm{~nm}$.

Retention times for $\mathrm{o}, \mathrm{p}^{\prime}$-DDD, o, $\mathrm{p}^{\prime}$-DDA, o, $\mathrm{p}^{\prime}$-DDE, and $\mathrm{p}, \mathrm{p}^{\prime}$-DDE (IS) were $8.5,4.2,9.9$, and $10.8 \mathrm{~min}$ respectively (Fig. S1, see section on supplementary data given at the end of this article).

\section{Patients}

A total of 15 ACC patients treated with mitotane including the index case (ten with palliative intention and five as adjuvant treatment) were included in this study. The study was approved by the Ethics Committee of the University of Würzburg (Nos 93/02 and 88/11), and written informed consent was obtained from all patients. Anonymized serum samples from routine laboratory analyses of healthy individuals without mitotane treatment were used to prepare lipoprotein pools not containing mitotane.

\section{Density gradient ultracentrifugation of lipoproteins}

Serum samples of the 14 ACC patients were collected during mitotane treatment and stored at $4{ }^{\circ} \mathrm{C}$ until density gradient ultracentrifugation.

The procedure for the separation of lipoprotein subclasses using iodixanol originally described by Graham et al. $(28,29)$ was adapted as follows. In total, $1.0 \mathrm{ml}$ serum, $1.24 \mathrm{ml}$ Hepes buffer saline (HBS) buffer $(10 \mathrm{mM}$ HEPES; $0.8 \% \mathrm{NaCl}$; pH7.4), and $0.54 \mathrm{ml}$ OptiPrep (60\% iodixanol) were transferred into a Beckman OptiSeal tube $(3.2 \mathrm{ml})$ and thoroughly mixed by gentle, repeated over-head rotation. Finally, the mixture was carefully overlayed with distilled water to fill the tube. The tubes were housed in a Beckman TLN100 rotor and centrifuged at $350000 \boldsymbol{g}$ for $0300 \mathrm{~h}$ at $15^{\circ} \mathrm{C}$ with acceleration program 9 and deceleration program 9 in a Beckman Optima E-max benchtop ultracentrifuge.
Gradients were collected using a Beckman gradient unloader, which pierces the tube bottom, a WatsonMarlow 520S/R precision peristaltic pump, and a Gilson (Villiers, France) fraction collector. A total of 20 fractions, each $0.16 \mathrm{ml}$, were collected by continuously pumping the gradient from the bottom of the tube to the fraction collector numbering the fractions from top (fraction 1) to bottom (fraction 20). The fractions of the gradient were pooled to obtain the following lipoprotein fractions: VLDL (fractions 1-2), IDL (fractions 3-4), LDL1 (fractions 5-8), LDL2 (fractions 9-11), LDL3 (fractions 12-13), HDL (fractions 14-17), and lipoprotein-depleted serum (fractions 18-20). In each of the lipoprotein fractions triglycerides, total cholesterol, LDL cholesterol, and HDL cholesterol were measured on the Cobas c501 (Roche) with the reagent kits from Roche. To isolate chylomicrons, ascites was mixed with HBS and centrifuged for $10 \mathrm{~min}$ at $100000 \mathrm{~g}$.

As controls, 14 anonymous samples from individuals without mitotane treatment were fractionated in the same manner and pooled as described.

\section{Cell culture}

The adherent variant of the ACC cell line NCI-H295 (NCI-H295R) was cultured as described (30).

\section{Cell-based assays}

Viability testing using WST-1 reagent was performed according to the manufacturer's protocol (Roche). To assess the efficacy of mitotane in chyle, NCI-H295 cells have been incubated with medium containing increasing concentrations of mitotane dissolved in ethanol or the equivalent quantity of mitotane from chyle from the index patient. Quantification of mitotane in chyle was performed by HPLC as described above. To assess the impact of lipoproteins on mitotane efficacy, equal quantities of lipids (cholesterol+triglycerides) from the VLDL, LDL2, and HDL2 fractions of pooled control serum samples were added to serum-free cell culture medium, and either diluent, 25 or $50 \mu \mathrm{M}$ mitotane was added. The viability of the control cells cultivated in serum-free medium and medium containing fetal calf serum was very similar $(100 \pm 8.3$ vs $91.34 \pm 4.4 \%)$. Cortisol was measured in the supernatant with an Immulite2000 analyzer (Siemens Healthcare Diagnostics, Erlangen, Germany). Quantitative real-time PCR was performed as described (6). 


\section{Statistical analysis}

Patients were divided into high and low lipid groups according to the median of their total lipid (cholesterol+ triglyceride) serum concentration. Statistical analyses were made using Prism 6.0 (GraphPad, La Jolla, CA, USA). Statistical differences between groups were calculated using either Fisher's $t$-test or ANOVA non-parametric test (Kruskal-Wallis) depending on the number of data sets. Correlation analyses were carried out using the nonparametric Spearman $r$ correlation test. All error bars show S.D. Box plots indicate mean values and quartiles, and the whiskers represent the minimal and maximal values.

\section{Results}

\section{Case description}

A 29-year-old female ACC patient was admitted to the hospital for disease staging after chemotherapy with gemcitabine, capecitabine, and mitotane (Table 1, index case) (31). The patient complained about abdominal discomfort and abdominal swelling. An 18FDG-PET-CT revealed abundant ascites (Fig. 1A and B). Paracentesis was performed and 4.11 opaque ascites were removed. Cytology showed abundant mast cells and lymphocytes without detection of tumor cells. Chemistry demonstrated $48550 \mu \mathrm{g} / \mathrm{ml}$ triglycerides consistent with the clinical diagnosis of chylous ascites.
In the absence of detectable peritoneal carcinosis and gross liver metastases, we suspected misplaced pedicle screw implants to be causative of chylous ascites keeping in mind the close proximity of Th11 screws to central abdominal lymph vessels. Vertebra L1 had been replaced and spondylodesis of Th11-L3 performed due to ACC metastasis to L1 (Fig. 1A, B, C and D). The chylomicron fraction isolated by ultracentrifugation contained $179840 \mu \mathrm{g} / \mathrm{ml}$ triglycerides and $54400 \mu \mathrm{g} / \mathrm{ml}$ cholesterol (Fig. 1E).

Mitotane was discontinued, and the patient was placed on a fat-reduced diet with medium-chain fatty acid supplementation. This resulted in nearly complete remission of ascites until the next tumor evaluation 3 months thereafter.

\section{Mitotane and its metabolites are abundant in chylomicrons}

We employed HPLC to quantify mitotane and its metabolites $\mathrm{o}, \mathrm{p}^{\prime}$-DDA and $\mathrm{o}, \mathrm{p}^{\prime}$-DDE in chyle. Strikingly, we detected $197 \mathrm{mg} / \mathrm{l}$ mitotane, $53 \mathrm{mg} / \mathrm{l}$ o,p'-DDA, and $51 \mathrm{mg} / \mathrm{lo}$, $\mathrm{p}^{\prime}$-DDE in the ascites specimen (Fig. 1F). At the time of paracentesis, the serum level of mitotane in this patient was $5.5 \mathrm{mg} / \mathrm{l}$.

\section{Mitotane bound to chylomicrons has reduced activity in $\mathrm{NCl}-\mathrm{H} 295$ cells}

To determine the biological activity of chylomicronassociated mitotane, we made use of the NCI-H295 ACC cell line. Equal amounts of chylomicron-bound mitotane

Table 1 Patient characteristics. The patient with chylous ascites is termed 'index case'.

\begin{tabular}{|c|c|c|c|c|c|c|c|c|}
\hline PID & Sex & $\begin{array}{c}\text { Age } \\
\text { (years) }\end{array}$ & $\begin{array}{l}\text { ENSAT } \\
\text { stage }\end{array}$ & $\begin{array}{l}\text { Treatment } \\
\text { intention }\end{array}$ & $\begin{array}{c}\text { Serum } \\
\text { mitotane } \\
(\mathrm{mg} / \mathrm{l})\end{array}$ & $\begin{array}{c}\text { Serum } \\
\text { triglycerides } \\
(\mu \mathrm{g} / \mathrm{ml})\end{array}$ & $\begin{array}{c}\text { Serum } \\
\text { cholesterol } \\
(\mu \mathrm{g} / \mathrm{ml})\end{array}$ & $\begin{array}{c}\text { Sum serum } \\
\text { cholesterol + } \\
\text { triglycerides } \\
(\mu \mathrm{g} / \mathrm{ml})\end{array}$ \\
\hline Index case & $\mathrm{F}$ & 29.1 & 4 & Palliative & 5.1 & 1230 & 820 & 2050 \\
\hline 19 & $\mathrm{M}$ & 54.7 & 2 & Adjuvant & 12.1 & 1160 & 3493 & 4653 \\
\hline 20 & $F$ & 75.9 & 3 & Adjuvant & 20.1 & 1213 & 4197 & 5410 \\
\hline 22 & $\mathrm{M}$ & 44.0 & 4 & Palliative & 16.6 & 802 & 3096 & 3898 \\
\hline 23 & $\mathrm{~F}$ & 37.1 & 4 & Palliative & 6.6 & 678 & 1862 & 2540 \\
\hline 31 & $\mathrm{M}$ & 46.4 & 4 & Palliative & 7.7 & 891 & 3174 & 4065 \\
\hline 32 & $\mathrm{M}$ & 52.7 & 2 & Adjuvant & 12.5 & 1618 & 1877 & 3495 \\
\hline 34 & $F$ & 50.4 & 4 & Palliative & 25.1 & 739 & 3003 & 3742 \\
\hline 38 & $\mathrm{M}$ & 69.7 & 4 & Palliative & 8.1 & 2498 & 2040 & 4538 \\
\hline 40 & $\mathrm{M}$ & 54.5 & 4 & Palliative & 14.3 & 2024 & 2310 & 4334 \\
\hline 42 & $\mathrm{M}$ & 63.5 & 4 & Palliative & 20.2 & 3779 & 2755 & 6534 \\
\hline 43 & $\mathrm{M}$ & 63.1 & 4 & Palliative & 17.0 & 743 & 1876 & 2619 \\
\hline 46 & $\mathrm{M}$ & 57.3 & 2 & Adjuvant & 2.3 & 531 & 2512 & 3043 \\
\hline 52 & $\mathrm{M}$ & 54.8 & 3 & Adjuvant & 3.4 & 1504 & 2959 & 4463 \\
\hline 55 & $\mathrm{M}$ & 50.6 & 4 & Palliative & 5.2 & 994 & 1954 & 2948 \\
\hline Median & & & & & & 1160 & 2512 & 3898 \\
\hline Normal range & & & & & & $740-1720$ & $1300-2200$ & \\
\hline
\end{tabular}



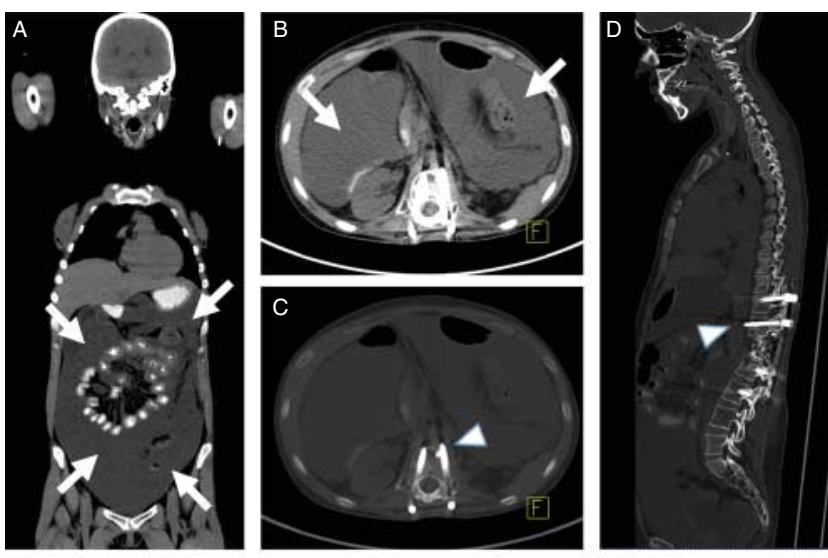

E

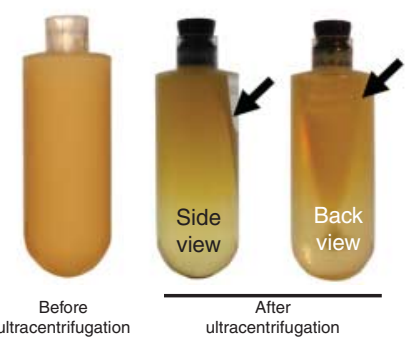

F

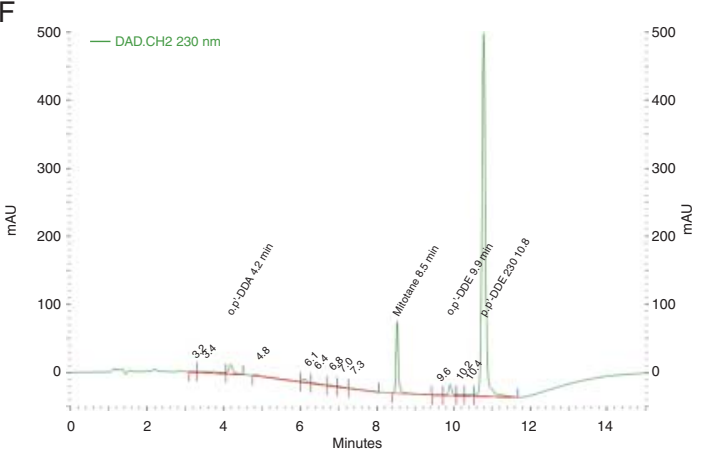

G
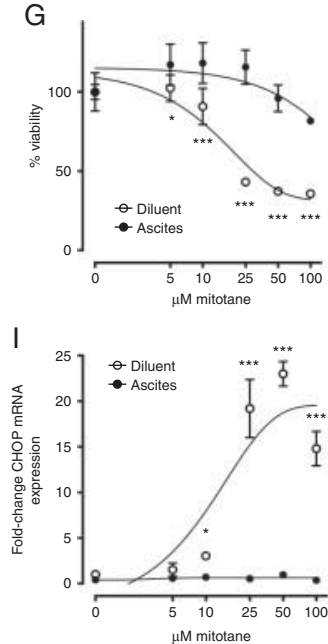
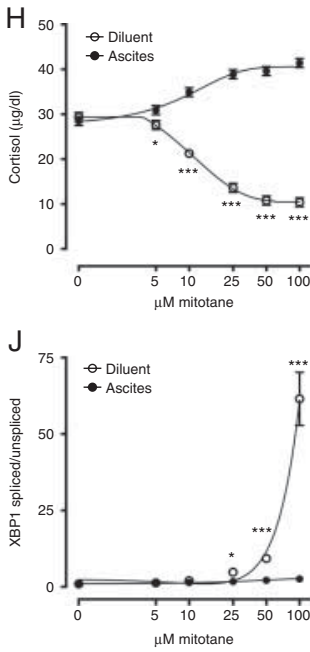

from the index patient and mitotane diluted in ethanol were added to cell culture medium, and cell viability was assessed by WST-1 assay. We found the EC50 after $24 \mathrm{~h}$ to be $15.4 \mu \mathrm{M}$ for free mitotane and $>100 \mu \mathrm{M}$ for chylomicron-bound mitotane (Fig. 1G). Accordingly, free mitotane but not chylomicron-associated mitotane led to inhibition of cortisol synthesis by more than fourfold (from 1.45- to 0.35-fold compared to baseline).

ER stress, the underlying molecular effector mechanism of both impaired steroidogenesis and apoptosis, was strongly activated by free mitotane. ER stress marker C/EBP homologous protein (CHOP) mRNA was induced 19.2 \pm 3.2 -fold, $23.0 \pm 1$.3-fold, and 14.8 \pm 1.9 -fold at 25,50 , and $100 \mu \mathrm{M}$ respectively. At variance, chylomicron-associated mitotane did not induce any changes of CHOP mRNA expression (Fig. 1J). Similarly, activation of X-box binding protein (XBP1) mRNA splicing indicative of ER stress was observed with free mitotane (4.8 \pm 0.1 -fold, $9.3 \pm 0.1$-fold, and $61.5 \pm 8.7$-fold with 25,50 , and $100 \mu \mathrm{M}$

\section{Figure 1}

Analysis of the index patient. Coronal (A), axial (B, C), and sagittal (D) slices of CT displayed in both soft tissue $(A, B)$ and bone (C, D) windows are given. The 29-year-old patient was referred for re-staging. Note important quantities of ascites in the abdomen ( $A, B$; arrows). Misplaced pedicle screws in close proximity to the chyle cistern were the likely cause of the chylous ascites (C, D; arrowheads). No intravenous contrast agent was administered due to chronic kidney disease caused by nephrectomy and previous platinum-based chemotherapy (5). Ultracentrifugation (E) proved ascites to contain chylomicrons (arrows) which float on buffer. (F) HPLC of chyle provided evidence of $0, p^{\prime}$-DDA (retention time $4.2 \mathrm{~min}$ ), mitotane (8.5 min), and o, $p^{\prime}$-DDE (9.9 min). p, $p^{\prime}$-DDE (10.8 min) served as internal standard. Viability of $\mathrm{NCl}-\mathrm{H} 295$ cells (G) was significantly less reduced when equal amounts of mitotane associated with chylomicrons (closed symbols) were used compared with mitotane dissolved in ethanol (open symbols). Cortisol secretion of $\mathrm{NCl}-\mathrm{H} 295$ cells $(\mathrm{H})$ exposed to equal amounts of mitotane associated with chylomicrons (closed symbols) was less reduced compared to mitotane dissolved in ethanol (open symbols). Expression of ER stress marker gene CHOP (I) and XBP1 mRNA splicing (J) was not increased in $\mathrm{NCl}-$ $\mathrm{H} 295$ cells exposed to mitotane associated with chylomicrons (closed symbols) but strongly increased in cells exposed to equal concentrations of mitotane in ethanol (open symbols). $* P<0.05$ and $* * * P<0.001$. 
mitotane respectively) but not with mitotane bound to chylomicrons $(P<0.001)$.

\section{The majority of circulating mitotane is bound to lipoproteins}

We next investigated the distribution of mitotane and its metabolites in serum lipoproteins in 14 ACC patients treated with mitotane (see Table 1 for patient characteristics) by subjecting serum samples to LipoDens density gradient ultracentrifugation. Patients were classified as high ( $>12.3 \mathrm{mg} / \mathrm{l})$ vs low mitotane $(<12.3 \mathrm{mg} / \mathrm{l})$ based on the median serum value and no significant difference in total triglycerides $(1180 \pm 663 \mu \mathrm{g} / \mathrm{ml}$ vs $1560 \pm 1094 \mu \mathrm{g} / \mathrm{ml}$; $P=0.5$; Fig. 2A), and total cholesterol $(2571 \pm 650 \mu \mathrm{g} / \mathrm{ml}$ vs $2731 \pm 816 \mu \mathrm{g} / \mathrm{ml} ; P=0.9$; Fig. $2 \mathrm{~B}$ ) was observed.

In the VLDL fraction, $21.7 \pm 21.4 \%$ of total mitotane (Fig. 2C) was found, $1.9 \pm 0.8 \%$ in IDL, and $8.9 \pm 5.5 \%$ in LDL1, $18.9 \pm 9.6 \%$ in LDL2, $10.1 \pm 4.0 \%$ in LDL3, and $26.3 \pm 13.0 \%$ in HDL2 lipoprotein fractions. Only $12.3 \pm$ $5.5 \%$ were present in the lipoprotein-depleted fraction. In contrast $\mathrm{o}, \mathrm{p}^{\prime}$-DDA (Fig. 2D) was mostly present in the HDL2 fraction $(21.9 \pm 6.9 \%)$ and in the lipoproteindepleted fraction $(68.1 \pm 8.8 \%)$. o, $\mathrm{p}^{\prime}$-DDE (Fig. 2E) distribution was similar to mitotane (VLDL: $16.4 \pm$ 14.3\%; IDL: $2.1 \pm 1.6 \%$; LDL1: $7.9 \pm 4.2 \%$; LDL2: $14.2 \pm$ 5.5\%; LDL3: 9.3 $\pm 2.9 \%$; HDL2: $21.2 \pm 8.6 \%$; and lipoprotein-depleted: $28.7 \pm 6.7 \%)$. We next determined concentrations of mitotane and lipids in individual lipoprotein classes and examined the impact of lipid composition on mitotane binding to individual lipoproteins. Mitotane content of lipoproteins showed a positive correlation with both cholesterol $(r=0.77 ; 95 \%$ CI of regression curve $=$ $0.67-0.84$; Fig. 2F) and triglyceride content $(r=0.59 ; 95 \%$ $\mathrm{CI}=0.45-0.71$; Fig. 2G). Best correlation was obtained for the sum value of triglycerides and cholesterol $(r=0.83$; 95\% CI=0.75-0.88; Fig. 2H). Accordingly, relative abundance of mitotane in cholesterol and triglyceride-rich VLDL particles was higher in the group of patients with high total cholesterol and triglyceride serum concentrations $(32.0 \pm 25.0 \%$ vs $11.4 \pm 11.1 ; P<0.05$; Fig. $2 \mathrm{C}$; low lipid group: blue symbols; high lipid group: red symbols).

A moderate correlation was found for total mitotane and lipoprotein free mitotane (Fig. 2I) $(r=0.68$; 95\% CI= $0.22-0.89)$. Total serum lipids inversely correlated with lipoprotein free mitotane $(r=-0.33 ; 95 \% \mathrm{CI}=-0.74$ 0.26; Fig. 2J).
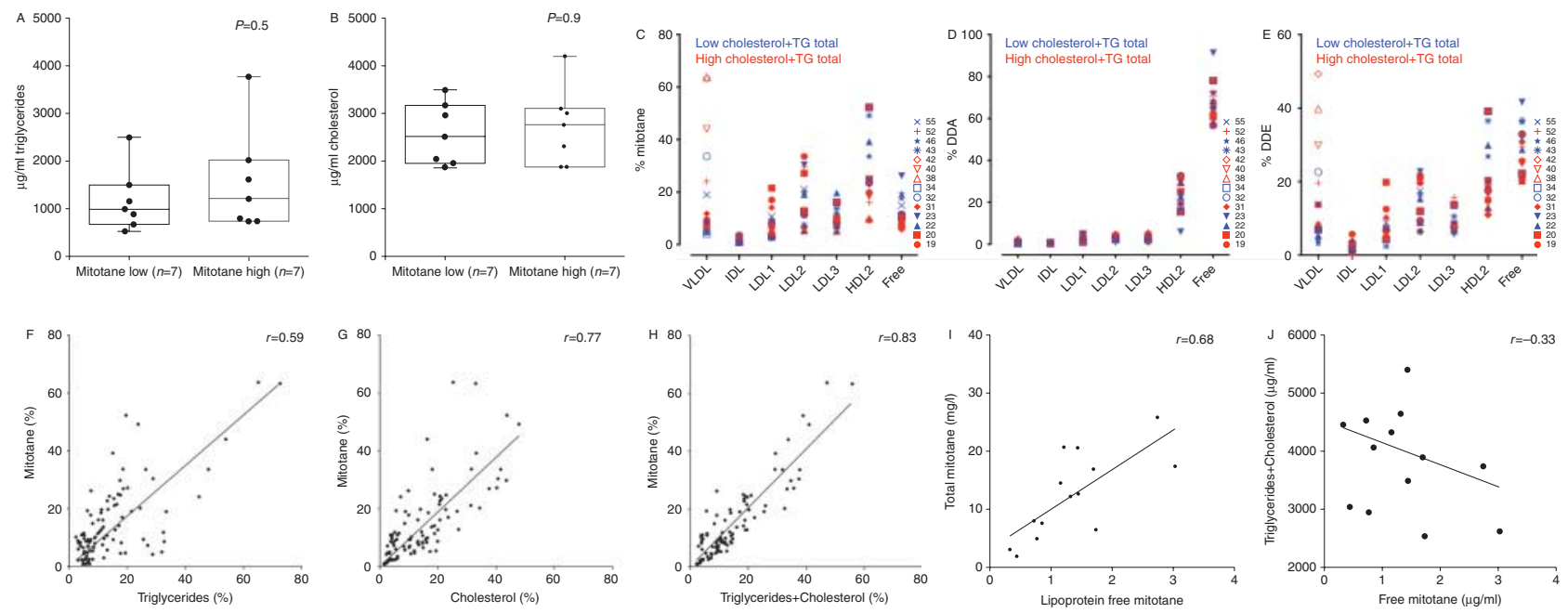

\section{Figure 2}

Lipoprotein association of mitotane and its metabolites. Serum triglycerides (A) and serum cholesterol (B) did not differ significantly between patients with low (left) and high (right) mitotane serum concentrations. Lipoprotein binding of mitotane (C), o, $\mathrm{p}^{\prime}$-DDA (D), o, $\mathrm{p}^{\prime}$-DDE (E) in patients with high serum lipids (triglycerides and cholesterol, red), and low serum lipids (blue) reveals differential association of mitotane and $o, p^{\prime}-D D E$ with lipoproteins, whereas $0, p^{\prime}-D D A$ is mostly present in lipoprotein-depleted and HDL2 fractions. Lipoprotein association of mitotane correlates with cholesterol (F) and triglycerides (G) in the respective fraction. Best correlation is obtained with combined cholesterol and triglycerides $(\mathrm{H})$. Lipoproteinfree mitotane concentration correlates with total mitotane serum concentration (I) and negatively correlates with serum cholesterol and triglyceride concentration (J). 


\section{Mitotane efficacy can be reduced by co-incubation with lipoproteins}

To examine the impact of lipoproteins on mitotane efficacy, NCI-H295 cells were exposed to 25 and $50 \mu \mathrm{M}$ mitotane and increasing quantities of lipids from isolated mitotane-free human lipoproteins (Fig. 3). As expected, mitotane treatment in diluent significantly reduced
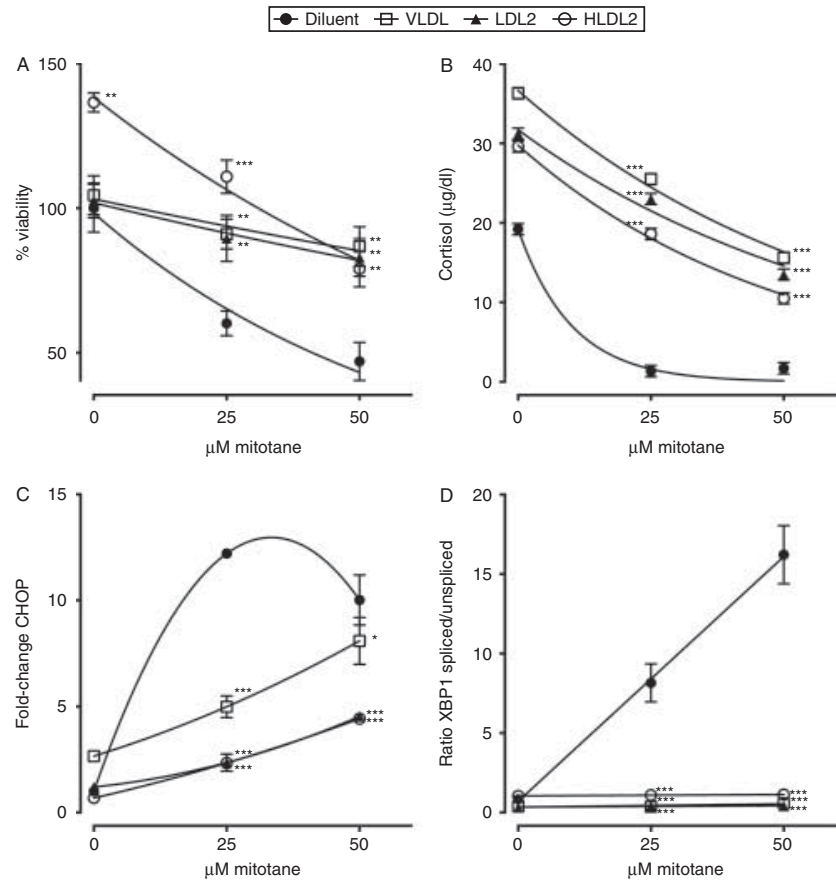

Figure 3

In vitro efficacy of lipoprotein-associated and lipoprotein-free mitotane. Normal mitotane-free lipoprotein fractions (VLDL, $\mathrm{LDL} 2$, and HDL2) were added to 25 and $50 \mu \mathrm{M}$ mitotane and viability (A), cortisol secretion (B), CHOP mRNA expression (C), and XBP1 mRNA splicing in NCl-H295 cells measured. Addition of VLDL (open square) and LDL2 (black triangle) increased viability compared to equal concentrations of mitotane in ethanol. Addition of HDL2 (open circle) increased viability compared to solvent control, but addition of mitotane decreased viability proportionally more than LDL2 and VLDL. Similarly, inhibition of cortisol secretion by mitotane was alleviated through addition of lipoproteins (B). CHOP expression (C) likewise reduces by lipoproteins compared to lipoprotein-free mitotane. The decrease of CHOP expression at $50 \mu \mathrm{M}$ lipoprotein-free mitotane compared to $25 \mu \mathrm{M}$ has been observed previously and may be associated with feedback inactivation through downstream events. XBP1 mRNA splicing, an early event of ER-stress, is completely abolished when lipoproteins are added. ${ }^{*} P<0.05, * * P<0.01$ and $* * * P<0.001$. viability of NCI-H295 cells after $6 \mathrm{~h}$ treatment to $60.2 \pm$ $4.3 \%$ and $47.0 \pm 6.6 \%$ for 25 and $50 \mu \mathrm{M}$ respectively (Fig. 3A). In contrast, addition of VLDL particles rescued cell viability to $91.0 \pm 5.2 \%$ and $86.8 \pm 6.8 \%$ for 25 and $50 \mu \mathrm{M}$ of baseline $(P<0.05$ each). Similarly, addition of LDL2 particles rescued cell viability to $89.5 \pm 7.9 \%$ and $82.9 \pm 6.5 \%$ for 25 and $50 \mu \mathrm{M}$ of baseline $(P<0.05$ each). Of note, HDL2 alone increased cell viability compared to other lipoproteins and cell culture medium to $136.5 \pm 3.3 \%$ (compared to solvent control; $P<0.05)$, but addition of mitotane suppressed cell viability even more strongly than co-incubation with VLDL and LDL2 particles. Similarly, mitotane alone but not mitotane co-incubated with lipoproteins inhibited cortisol secretion in the supernatant (viability $25 \mu \mathrm{M}$ mitotane: $7.0 \pm 0.3 \%$ and $50 \mu \mathrm{M}$ mitotane $8.9 \pm 0.7 \%$ vs an average viability of $68.9 \pm$ $5.5 \%$ and $40.6 \pm 4.4 \%$ respectively, $P<0.001$, after lipoprotein addition) (Fig. 3B). Cortisol production in the presence of lipoproteins was generally higher, as the lipoproteins represent an external source of substrate cholesterol for steroidogenesis. The role of HDL, LDL, and VLDL in promoting adrenal steroidogenesis has been quite well established $(32,33,34,35)$.

We next studied the impact of added lipoproteins on mitotane-induced ER stress gene expression and found CHOP expression after co-incubation with mitotane to be reduced from $12.2 \pm 0.2$-fold $(25 \mu \mathrm{M}$ mitotane) to $4.9 \pm$ 0.5-fold (VLDL added), 2.3 \pm 0.4 -fold (LDL2 added), and $2.3 \pm 0.1$-fold (HDL2 added). XBP1 mRNA splicing was completely blunted after co-treatment with lipoproteins (25 $\mu \mathrm{M}$ mitotane: 8.2 \pm 1.2-fold; VLDL added: 0.4 \pm 0.02-fold; LDL2 added: 0.4 \pm 0.04 -fold; HDL2 added: 1.1 \pm 0.04 -fold).

\section{Discussion}

Mitotane is routinely administered orally for adjuvant and palliative treatment of ACC. The physicochemical properties of mitotane are characterized by a high degree of lipophilicity. It is current clinical practice to advice patients to take oral mitotane together with fat-containing food such as whole-milk yogurt in order to improve resorption and increase the likelihood of achieving therapeutic drug concentrations. In this study, we exploited the availability of chyle in an ACC patient treated with mitotane to study association of mitotane and its metabolites with lipoproteins.

To unambiguously prove that the ascites removed from the index patient contained chyle, we performed ultracentrifugation to isolate chylomicrons. The high content of triglycerides and cholesterol in the floating fraction after ultracentrifugation confirmed the diagnosis 
of chylous ascites. The precise cause of ascites could not decisively be clarified. However, it is likely that the physical activity of the patient (horse riding) and the known misplacement of pedicle screws in the Th11 vertebra led to injury of large abdominal lymph vessels. During follow-up in this patient, near complete remission was achieved by conservative treatment.

We found chyle to contain large amounts of mitotane indicating that mitotane absorption from the intestinal lumen largely occurs as a by-load of nutrient lipids and more specifically long-chain triglycerides. We were surprised to also detect in the chyle significant amounts of both o, $\mathrm{p}^{\prime}$-DDA and $\mathrm{o}, \mathrm{p}^{\prime}$-DDE, the two best described mitotane metabolites. $\mathrm{o}, \mathrm{p}^{\prime}$-DDA concentrations are known to be up to tenfold higher than the parent substance in serum, whereas $\mathrm{o}, \mathrm{p}^{\prime}$-DDE is less abundant (12). Rat liver microsomes have been shown to be capable of mitotane transformation to the inactive metabolite o,p'-DDA $(36,20)$. Circumstantial evidence of mitotane transformation in the liver of humans is suggested by its strong inducing effect on hepatic cytochrome P450 enzymes $(37,38,39,40)$. To our knowledge, intestinal metabolization of mitotane has not yet been described, and the origin of $o, p^{\prime}$-DDE in serum is not precisely known. Therefore, our finding of $o, \mathrm{p}^{\prime}$-DDA and $\mathrm{o}, \mathrm{p}^{\prime}$-DDE in chyle suggests that mitotane biotransformation may occur already during resorption in the intestine. The mechanisms underlying the differences in relative abundance of $\mathrm{o}, \mathrm{p}^{\prime}$-DDA and $\mathrm{o}, \mathrm{p}^{\prime}$-DDE in serum vs chyle can not be clarified from this data. On the one hand, beyond intestinal mitotane metabolism, hepatic and potentially extra-hepatic metabolism of mitotane may contribute to the overall high abundance of o, $\mathrm{p}^{\prime}$-DDA, since the amount of $\mathrm{o}, \mathrm{p}^{\prime}$-DDA recovered from the chyle was only around a quarter of that of mitotane and not tenfold higher as most often found in the serum of mitotane-treated patients. On the other hand, $o, p^{\prime}$-DDE levels were similar to those of $o, p^{\prime}$-DDA in chyle, while in patients ${ }^{\prime}$ serum, it is ten times less then that of mitotane. This suggests that mitotane metabolization in the gut may be directed more toward production of $\mathrm{o}, \mathrm{p}^{\prime}$-DDE. On the other hand, o, $\mathrm{p}^{\prime}$-DDE might be further metabolized in organs such as the liver, resulting in only trace amounts present in the serum. As a third alternative, the relatively small proportion of circulating mitotane vs $\mathrm{o}, \mathrm{p}^{\prime}$-DDA may be attributable in part to diffusion into lipid-rich tissues. We cannot exclude at this point that $o, p^{\prime}$-DDA and $o, p^{\prime}$-DDE undergo an enterohepatic circulation; hence, chyle would be enriched in $\mathrm{o}, \mathrm{p}^{\prime}$-DDA, resulting from hepatic transformation. However, no significant quantities of $\mathrm{o}, \mathrm{p}^{\prime}$-DDA have been reported in feces $(21,41)$. Conversely, intestinal microsomes are highly active in xenobiotic transformation and CYP3A-mediated metabolism is prevalent in intestinal mucosa $(42,43)$. Therefore, intestinal exposure to mitotane may lead to enzyme induction and metabolic transformation already during absorption. Inhibition of intestinal (and hepatic) CYP3A enzymes may therefore shorten the time interval to reach therapeutic serum levels of mitotane (44). There are already inhibitors of CYP3A4 used in the clinic like ritonavir or cobicistat, which are pharmacokinetic enhancers of protease inhibitors $(45,46)$. Our observation is limited by the availability of only one suitable case. Therefore, animal studies - preferably in non-rodents (47) - are required to confirm our finding.

Mitotane association with lipoproteins was reported earlier (23), and mitotane-induced increase of serum lipids is frequent (48).

In our study, serum lipids were similar between patients with high and low mitotane concentrations precluding selection bias. We found the vast majority of mitotane to be bound to lipoproteins with only $12.3 \pm$ $5.5 \%$ lipoprotein-free mitotane. Distribution of mitotane between serum lipoproteins was variable and depended on the lipid status of the patient. A narrow correlation was observed between lipoprotein-associated mitotane and total cholesterol + triglyceride concentration in the VLDL fraction. A similar distribution was seen for $\mathrm{o}, \mathrm{p}^{\prime}$-DDE. In contrast, $o, p^{\prime}$-DDA was preferably detected in HDL2 and lipoprotein-depleted fraction. Hence, lipoprotein binding most likely is a result of the different lipophilicity of the parent compound and metabolites rather than specific binding to lipoprotein constituents (so, mitotane and $\mathrm{o}, \mathrm{p}^{\prime}$-DDE might just be having a higher affinity for lipids while $o, p^{\prime}$-DDA is not lipophilic).

This is in good agreement with data by Gebhardt et al. (23) but not completely identical to the very recent data by Hescot et al. (25). In the latter paper, serum lipids were not measured; therefore, it could be that relatively low overall lipid and especially triglyceride levels in the study population may have led to relative high lipoprotein-free mitotane levels. Our patient samples cover a range of physiological and elevated lipid concentrations potentially explaining this difference. Moreover, care was applied in our study to avoid freeze-thaw cycles which are known to potentially impair lipoprotein integrity. It is unclear whether this was the case in the work by Hescot et al. Of note, we found free mitotane to correlate with total serum mitotane and to inversely correlate with total cholesterol+triglyceride concentrations, suggesting that lipoproteins constitute a circulating pool of mitotane in 
the serum. From a pharmacological perspective, our combined clinical data can be interpreted in several ways: one possibility is that mitotane bound to chylomicrons, or their remnants enters hepatocytes and is incorporated in triglyceride-rich VLDL and cholesterolrich LDL and HDL particles. Alternatively, mitotane may be exchanged between lipoproteins passively which is likely given the close correlation of mitotane and lipid content of lipoproteins. We cannot exclude however that shuttling proteins contribute to exchange of mitotane and its metabolites between the different lipoproteins.

Human adrenocortical cells mainly rely on LDL cholesterol for steroid synthesis, but HDL cholesterol is a relevant source of cholesterol as well (49). Therefore, it is tempting to speculate that mitotane enters adrenocortical cells using HDL and/or LDL particles as a Trojan horse. However, our in vitro data employing the NCI-H295 model cell line contradict this hypothesis. Chylomicron-associated mitotane failed to impair viability and reduce steroidogenesis even at high concentrations. Given the correlation of mitotane and combined cholesterol and triglyceride concentration, we decided to add lipoproteins to defined concentrations of mitotane and assess the consequences at gene expression level and in terms of viability and steroidogenesis. By normalizing for lipid content, we found that VLDL and LDL particles alleviated the effect of mitotane on cell viability. HDL particles alone increased viability. HDL particles are known to be taken up by adrenocortical cells through the scavenger receptor B1 (49) and promote cell growth and proliferation by activation of the PI3 kinase/Akt pathway (50). However, a proportional decrease of viability was seen when mitotane was added. The notion of blunted response to mitotane in the presence of lipoproteins was even more clear when steroid hormone production and transcriptional up-regulation of ER stress markers CHOP and XBP1 mRNA splicing, two early steps during mitotane action, were assessed (6). Together these data provide compelling evidence that lipoprotein-associated mitotane is less active in reducing cell viability compared to unbound mitotane and likely functions as a buffer or sink which may also prevent mitotane efficacy in vivo in some cases.

The data presented here have significant clinical consequences. First, patients with a disposition toward low serum lipids may be unable to achieve total serum concentrations of mitotane deemed effective. Conversely, patients with severe hypertriglyceridemia - as sometimes observed during mitotane treatment for unknown reasons - are likely to have overall higher mitotane serum concentrations with albeit lower lipoprotein-free mitotane. This is consistent with the clinical experience that excessively high mitotane blood concentrations are tolerated in hyperlipidemia without significant side effects. Efficacy of mitotane in these patients has not yet been studied systematically. Secondly, our data together with the study by Hescot et al. (25) put into question the current threshold of $14 \mathrm{mg} / \mathrm{l}$ of total mitotane in serum that has been demonstrated to be associated with superior treatment response. It may improve patient care to instead quantify lipoprotein-free mitotane in order to better balance toxicity and efficacy.

Clinically, two obvious consequences remain to be investigated: we cannot, at present, finally argue for or against a particular diet for patients taking mitotane. Increased dietary lipids may be expected to increase total serum lipids but fail to increase actual lipoprotein-free mitotane concentration. A pharmacokinetic study of lipoprotein-free mitotane concentration in a fasting state vs taken with a meal could solve this issue. Pharmacologic lowering of triglycerides and cholesterol may be another approach to increase the levels of lipoprotein-free mitotane. Though, we have reported that - at low mitotane concentrations - hydroxymethylglutaryl-CoA reductase inhibitors counteract cytotoxic effects of mitotane on adrenal cortex cells by lowering concentrations of free intracellular cholesterol (6) which induces lipotoxic ER stress. Moreover, it remains to be demonstrated that administration of lipid-lowering drugs indeed increases lipoprotein-free mitotane.

In conclusion, we found that the intestine likely contributes to metabolic transformation of mitotane and incorporation into chylomicrons. We confirm previous data indicating that lipoprotein-free mitotane is the active form of the drug. Lipoproteins decrease the bioavailability of active mitotane. A better understanding of the impact of food and co-administration of lipid-lowering drugs on lipoprotein-free mitotane concentrations is necessary to improve patient care. We additionally propose a prospective clinical trial to study disease response in relation to total and lipoprotein-free mitotane concentrations.

Supplementary data

This is linked to the online version of the paper at http://dx.doi.org/10.1530/ EJE-15-0946.

Declaration of interest

$M$ Fassnacht received a lecture fee from HRA Pharma and has been a co-investigator of an HRA Pharma sponsored clinical trial on the pharmacokinetics of mitotane. 
Funding

This publication was supported by grants of the Deutsche Forschungsgemeinschaft (grant KR4371/1-1 to M K, FA 466/3-1 to M F) and a fellowship of the Comprehensive Cancer Center Mainfranken to M K.

Acknowledgment

We are grateful to Michaela Haaf for maintaining the ACC database.

\section{References}

1 Else T, Kim AC, Sabolch A, Raymond VM, Kandathil A, Caoili EM, Jolly S, Miller BS, Giordano TJ \& Hammer GD. Adrenocortical carcinoma. Endocrine Reviews 201435 282-326. (doi:10.1210/ er.2013-1029)

2 Fassnacht M, Libe R, Kroiss M \& Allolio B. Adrenocortical carcinoma: a clinician's update. Nature Reviews. Endocrinology 20117 323-335. (doi:10.1038/nrendo.2010.235)

3 Bergenstal D, Lipsett M, Moy R \& Hertz R. Regression of adrenal cancer and suppression of adrenal function in men by o,p'-DDD. Transactions of American Physicians 195972341.

4 Berruti A, Baudin E, Gelderblom H, Haak HR, Porpiglia F, Fassnacht M, Pentheroudakis G \& ESMO Guidelines Working Group . Adrenal cancer: ESMO Clinical Practice Guidelines for diagnosis, treatment and followup. Annals of Oncology 201223 vii131-vii138. (doi:10.1093/annonc/ mds231)

5 Fassnacht M, Terzolo M, Allolio B, Baudin E, Haak H, Berruti A, Welin S, Schade-Brittinger C, Lacroix A, Jarzab B et al. Combination chemotherapy in advanced adrenocortical carcinoma. New England Journal of Medicine 2012366 2189-2197. (doi:10.1056/NEJMoa1200966)

6 Sbiera S, Leich E, Liebisch G, Sbiera I, Schirbel A, Wiemer L, Matysik S, Eckhardt C, Gardill F, Gehl A et al. Mitotane inhibits sterol-O-acyl transferase 1 triggering lipid-mediated endoplasmic reticulum stress and apoptosis in adrenocortical carcinoma cells. Endocrinology, 2015 en20151367.

7 Hahner S \& Fassnacht M. Mitotane for adrenocortical carcinoma treatment. Current Opinion in Investigational Drugs 20056 386-394.

8 Igaz P, Tombol Z, Szabo PM, Liko I \& Racz K. Steroid biosynthesis inhibitors in the therapy of hypercortisolism: theory and practice. Current Medicinal Chemistry 200815 2734-2747. (doi:10.2174/ 092986708786242921)

9 Haak HR, Hermans J, van de Velde CJ, Lentjes EG, Goslings BM, Fleuren GJ \& Krans HM. Optimal treatment of adrenocortical carcinoma with mitotane: results in a consecutive series of 96 patients. British Journal of Cancer 199469 947-951. (doi:10.1038/bjc.1994.183)

10 Baudin E, Pellegriti G, Bonnay M, Penfornis A, Laplanche A, Vassal G \& Schlumberger M. Impact of monitoring plasma 1,1-dichlorodiphenildichloroethane (o, $\mathrm{p}^{\prime} \mathrm{DDD}$ ) levels on the treatment of patients with adrenocortical carcinoma. Cancer 200192 1385-1392. (doi:10.1002/ 1097-0142(20010915)92:6<1385::AID-CNCR1461>3.0.CO;2-2)

11 Malandrino P, Al Ghuzlan A, Castaing M, Young J, Caillou B, Travagli JP, Elias D, de Baere T, Dromain C, Paci A et al. Prognostic markers of survival after combined mitotane- and platinum-based chemotherapy in metastatic adrenocortical carcinoma. EndocrineRelated Cancer 201017 797-807. (doi:10.1677/ERC-09-0341)

12 Hermsen IG, Fassnacht M, Terzolo M, Houterman S, den Hartigh J, Leboulleux S, Daffara F, Berruti A, Chadarevian R, Schlumberger M et al. Plasma concentrations of $o, p^{\prime} \mathrm{DDD}, \mathrm{o}, \mathrm{p}^{\prime} \mathrm{DDA}$, and $\mathrm{o}, \mathrm{p}^{\prime} \mathrm{DDE}$ as predictors of tumor response to mitotane in adrenocortical carcinoma: results of a retrospective ENS@T multicenter study. Journal of Clinical Endocrinology and Metabolism 201196 1844-1851. (doi:10.1210/jc.2010-2676)
13 Terzolo M, Baudin AE, Ardito A, Kroiss M, Leboulleux S, Daffara F, Perotti P, Feelders RA, deVries JH, Zaggia B et al. Mitotane levels predict the outcome of patients with adrenocortical carcinoma treated adjuvantly following radical resection. European Journal of Endocrinology 2013169 263-270. (doi:10.1530/EJE-13-0242)

14 Daffara F, De Francia S, Reimondo G, Zaggia B, Aroasio E, Porpiglia F, Volante M, Termine A, Di Carlo F, Dogliotti L et al. Prospective evaluation of mitotane toxicity in adrenocortical cancer patients treated adjuvantly. Endocrine-Related Cancer 200815 1043-1053. (doi:10.1677/ERC-08-0103)

15 Terzolo M, Pia A, Berruti A, Osella G, Ali A, Carbone V, Testa E, Dogliotti L \& Angeli A. Low-dose monitored mitotane treatment achieves the therapeutic range with manageable side effects in patients with adrenocortical cancer. Journal of Clinical Endocrinology and Metabolism $2000 \mathbf{8 5} 2234-2238$.

16 Terzolo M, Zaggia B, Allasino B \& De Francia S. Practical treatment using mitotane for adrenocortical carcinoma. Current Opinion in Endocrinology, Diabetes, and Obesity 201421 159-165. (doi:10.1097/ MED.0000000000000056)

17 Kerkhofs TM, Baudin E, Terzolo M, Allolio B, Chadarevian R, Mueller HH, Skogseid B, Leboulleux S, Mantero F, Haak HR et al. Comparison of two mitotane starting dose regimens in patients with advanced adrenocortical carcinoma. Journal of Clinical Endocrinology and Metabolism 201398 4759-4767. (doi:10.1210/jc.2013-2281)

18 Kerkhofs TM, Derijks LJ, Ettaieb H, den Hartigh J, Neef K, Gelderblom H, Guchelaar HJ \& Haak HR. Development of a pharmacokinetic model of mitotane: toward personalized dosing in adrenocortical carcinoma. Therapeutic Drug Monitoring 201537 58-65. (doi:10.1097/FTD.0000000000000102)

19 Moolenaar AJ, van Slooten H, van Seters AP \& Smeenk D. Blood levels of $\mathrm{o}, \mathrm{p}^{\prime}$-DDD following administration in various vehicles after a single dose and during long-term treatment. Cancer Chemotherapy and Pharmacology 19817 51-54. (doi:10.1007/BF00258213)

20 Hescot S, Paci A, Seck A, Slama A, Viengchareun S, Trabado S, Brailly-Tabard S, Al Ghuzlan A, Young J, Baudin E et al. The lack of antitumor effects of o, $\mathrm{p}^{\prime} \mathrm{DDA}$ excludes its role as an active metabolite of mitotane for adrenocortical carcinoma treatment. Hormones \& Cancer 20145 312-323. (doi:10.1007/s12672-014-0189-7)

21 Reif VD, Sinsheimer JE, Ward JC \& Schteingart DE. Aromatic hydroxylation and alkyl oxidation in metabolism of mitotane (o,p'-DDD) in humans. Journal of Pharmaceutical Sciences 197463 1730-1736. (doi:10.1002/jps.2600631113)

22 Mornar A, Sertic M, Turk N, Nigovic B \& Korsic M. Simultaneous analysis of mitotane and its main metabolites in human blood and urine samples by SPE-HPLC technique. Biomedical Chromatography 2012 26 1308-1314. (doi:10.1002/bmc.2696)

23 Gebhardt DO, Moolenaar AJ, van Seters AP, van der Velde EA \& Gevers Leuven JA. The distribution of o, $\mathrm{p}^{\prime}$-DDD (mitotane) among serum lipoproteins in normo- and hypertriglyceridemia. Cancer Chemotherapy and Pharmacology 199229 331-334. (doi:10.1007/ BF00685956)

24 Pohland RC \& Counsell RE. The role of high density lipoproteins in the biodistribution of two radioiodinated probes in the rat. Toxicology and Applied Pharmacology 198577 47-57. (doi:10.1016/0041-008X (85)90266-2)

25 Hescot S, Seck A, Guerin M, Cockenpot F, Huby T, Broutin S, Young J, Paci A, Baudin E \& Lombes M. Lipoprotein-free mitotane exerts high cytotoxic activity in adrenocortical carcinoma. Journal of Clinical Endocrinology and Metabolism 2015100 2890-2898. (doi:10.1210/ JC.2015-2080)

26 Maher VM, Trainer PJ, Scoppola A, Anderson JV, Thompson GR \& Besser GM. Possible mechanism and treatment of o,p'DDD-induced hypercholesterolaemia. Quarterly Journal of Medicine 199284 671-679.

27 Molnar GD, Nunn SL \& Tauxe WN. The effect of o,p'-DDD therapy on plasma cholesterol in adrenal carcinoma. Proceedings of the Staff Meetings. Mayo Clinic 196136 618-620. 
28 Graham JM, Higgins JA, Gillott T, Taylor T, Wilkinson J, Ford T \& Billington D. A novel method for the rapid separation of plasma lipoproteins using self-generating gradients of iodixanol. Atherosclerosis 1996124 125-135. (doi:10.1016/0021-9150(96)05797-8)

29 Graham JM, Griffin BA, Davies IG \& Higgins JA. Fractionation of lipoprotein subclasses in self-generated gradients of iodixanol. Methods in Molecular Medicine 200152 51-59.

30 Kroiss M, Reuss M, Kühner D, Johanssen S, Beyer M, Zink M, Hartmann M, Dhir V, Wudy SA, Arlt W et al. Sunitinib inhibits cell proliferation and alters steroidogenesis by down-regulation of HSD3B2 in adrenocortical carcinoma cells. Frontiers in Endocrinology, 20112.

31 Sperone P, Ferrero A, Daffara F, Priola A, Zaggia B, Volante M, Santini D, Vincenzi B, Badalamenti G, Intrivici C et al. Gemcitabine plus metronomic 5-fluorouracil or capecitabine as a second-/third-line chemotherapy in advanced adrenocortical carcinoma: a multicenter phase II study. Endocrine-Related Cancer 201017 445-453. (doi:10.1677/ ERC-09-0281)

32 Saha S, Graessler J, Schwarz PE, Goettsch C, Bornstein SR \& Kopprasch S. Modified high-density lipoprotein modulates aldosterone release through scavenger receptors via extra cellular signal-regulated kinase and Janus kinase-dependent pathways. Molecular and Cellular Biochemistry 2012366 1-10. (doi:10.1007/s11010-012-1274-2)

33 Xing Y, Rainey WE, Apolzan JW, Francone OL, Harris RB \& Bollag WB. Adrenal cell aldosterone production is stimulated by very-low-density lipoprotein (VLDL). Endocrinology 2012153 721-731. (doi:10.1210/ en.2011-1752)

34 Saha S, Schwarz PE, Bergmann S, Bornstein SR, Graessler J \& Kopprasch S. Circulating very-low-density lipoprotein from subjects with impaired glucose tolerance accelerates adrenocortical cortisol and aldosterone synthesis. Hormone and Metabolic Research 201345 169-172.

35 Saha S, Bornstein SR, Graessler J \& Kopprasch S. Very-low-density lipoprotein mediates transcriptional regulation of aldosterone synthase in human adrenocortical cells through multiple signaling pathways. Cell and Tissue Research 2012348 71-80. (doi:10.1007/ s00441-012-1346-3)

36 Pohland RC \& Counsell RE. In vitro and in vivo metabolism of a radioiodinated analog of 1-(2-chlorophenyl)-1-(4-chlorophenyl)2,-dichloroethane. Drug Metabolism and Disposition 198513 113-115.

37 van Erp NP, Guchelaar HJ, Ploeger BA, Romijn JA, Hartigh JD \& Gelderblom AJ. Mitotane has a strong and a durable inducing effect on CYP3A4 activity. European Journal of Endocrinology $2011 \mathbf{1 6 4}$ 621-626. (doi:10.1530/EJE-10-0956)

38 Kroiss M, Quinkler M, Lutz WK, Allolio B \& Fassnacht M. Drug interactions with mitotane by induction of CYP3A4 metabolism in the clinical management of adrenocortical carcinoma. Clinical Endocrinology 201175 585-591. (doi:10.1111/j.1365-2265. 2011.04214.x)
39 Chortis V, Taylor AE, Schneider P, Tomlinson JW, Hughes BA, O'Neil DM, Libe R, Allolio B, Bertagna X, Bertherat J et al. Mitotane therapy in adrenocortical cancer induces CYP3A4 and inhibits $5 \alpha$-reductase, explaining the need for personalized glucocorticoid and androgen replacement. Journal of Clinical Endocrinology and Metabolism 201398 161-171. (doi:10.1210/jc.2012-2851)

40 Theile D, Haefeli WE \& Weiss J. Effects of adrenolytic mitotane on drug elimination pathways assessed in vitro. Endocrine 201549 842-853. (doi:10.1007/s12020-014-0517-2)

41 Reif VD \& Sinsheimer JE. Metabolism of 1-(0-chlorophenyl)-1(p-chlorophenyl)-2,2-dichloroethane (o, $\mathrm{p}^{\prime}$-DDD) in rats. Drug Metabolism and Disposition 19753 15-25.

42 Thelen K \& Dressman JB. Cytochrome P450-mediated metabolism in the human gut wall. Journal of Pharmacy and Pharmacology 200961 541-558. (doi:10.1211/jpp.61.05.0002)

43 Krishna DR \& Klotz U. Extrahepatic metabolism of drugs in humans. Clinical Pharmacokinetics 199426 144-160. (doi:10.2165/00003088199426020-00007)

44 Won CS, Oberlies NH \& Paine MF. Influence of dietary substances on intestinal drug metabolism and transport. Current Drug Metabolism 201011 778-792. (doi:10.2174/138920010794328869)

$45 \mathrm{Xu}$ L \& Desai MC. Pharmacokinetic enhancers for HIV drugs. Current Opinion in Investigational Drugs 200910 775-786.

46 Sherman EM, Worley MV, Unger NR, Gauthier TP \& Schafer JJ. Cobicistat: review of a pharmacokinetic enhancer for HIV infection. Clinical Therapeutics 201537 1876-1893. (doi:10.1016/j.clinthera.2015. 07.022)

47 Jensen BL, Caldwell MW, French LG \& Briggs DG. Toxicity, ultrastructural effects, and metabolic studies with 1-(o-chlorophenyl)1-(p-chlorophenyl)-2,2-dichloroethane(o,p'-DDD) and its methyl analog in the guinea pig and rat. Toxicology and Applied Pharmacology 198787 1-9. (doi:10.1016/0041-008X(87)90078-0)

48 Gebhardt DO, Moolenaar AJ \& van Seters AP. Mitotane (o,p'-DDD) administration raises the serum level of high density lipoprotein (HDL) in normotriglyceridemia. Hormone and Metabolic Research 199325 240-241. (doi:10.1055/s-2007-1002086)

49 Martin G, Pilon A, Albert C, Valle M, Hum DW, Fruchart JC, Najib J, Clavey V \& Staels B. Comparison of expression and regulation of the high-density lipoprotein receptor SR-BI and the low-density lipoprotein receptor in human adrenocortical carcinoma NCI-H295 cells. European Journal of Biochemistry 1999261 481-491. (doi:10.1046/ j.1432-1327.1999.00296.x)

50 Murao K, Imachi H, Cao W, Yu X, Li J, Yoshida K, Ahmed RA, Matsumoto K, Nishiuchi T, Wong NC et al. High-density lipoprotein is a potential growth factor for adrenocortical cells. Biochemical and Biophysical Research Communications 2006344 226-232. (doi:10.1016/ j.bbrc.2006.03.131)

Received 21 September 2015

Revised 24 November 2015

Accepted 15 December 2015 